CLINICAL STUDY

\title{
Variation in the gene encoding Krüppel-like factor 7 influences body fat: studies of 14818 Danes
}

\author{
Dorit P Zobel ${ }^{1}$, Camilla H Andreasen ${ }^{1}$, Kristoffer S Burgdorf ${ }^{1}$, Ehm A Andersson ${ }^{1}$, Annelli Sandbæk ${ }^{2}$, \\ Torsten Lauritzen ${ }^{2}$, Knut Borch-Johnsen ${ }^{1,3,4}$, Torben Jørgensen ${ }^{3}$, Shiro Maeda ${ }^{5}$, Yusuke Nakamura ${ }^{5}$, Hans Eiberg ${ }^{6}$, \\ Oluf Pederse $\mathrm{e}^{1,4,7}$ and Torben Hansen ${ }^{1,8}$ \\ ${ }^{1}$ Steno Diabetes Center, Niels Steensens Vej 2, DK-2820 Gentofte, Copenhagen, Denmark, ${ }^{2}$ Department of General Practice. University of Aarhus, Aarhus, \\ DK-8000 Denmark, ${ }^{3}$ Research Centre for Prevention and Health, Glostrup University Hospital, Glostrup, Denmark, ${ }^{4}$ Faculty of Health Science, University \\ of Aarhus, Aarhus, Denmark, ${ }^{5}$ Center for Genomic Medicine, RIKEN, Yokohama, Kanagawa 230-0045, Japan, ${ }^{6}$ Institute of Medical Biochemistry and \\ Genetics, University of Copenhagen, Copenhagen, Denmark, ${ }^{7}$ Faculty of Health Science, University of Copenhagen, Copenhagen, Denmark and ${ }^{8}$ Faculty of \\ Health Science, University of Southern Denmark, Odense, Denmark
}

(Correspondence should be addressed to D P Zobel; Email: dpaj@steno.dk)

\begin{abstract}
Objective: KLF7 encodes Krüppel-like factor (KLF) 7, a member of the KLF family of transcription factors, initially shown to play important roles in cellular development and differentiation, and reported to be specifically involved in adipogenesis. Several single nucleotide polymorphisms (SNPs) have been identified in KLF7, of which the A-allele of rs 2302870 has been associated with type 2 diabetes in a Japanese population; however, a possible association of KLF7 SNPs with obesity has not been investigated. We aimed to identify variation in the putative promoter region, the coding regions, exon/intron boundaries, and 3'-UTR of KLF7, and to examine identified variants in relation to obesity, type 2 diabetes, and related quantitative traits in Danish individuals.

Methods: Identified variants were investigated for association with type 2 diabetes in 8777 individuals and with obesity in 14818 individuals.

Results: We identified four common SNPs in low pairwise linkage disequilibrium; three in the putative promoter region $(-1119 \mathrm{G}>\mathrm{A},-963 \mathrm{C}>\mathrm{A}(\mathrm{rs} 7568369)$, and $-614 \mathrm{G}>\mathrm{A})$ and IVS2 + $35092 \mathrm{~A}>$ $\mathrm{C}$ (rs2302870). We failed to confirm an association between rs2302870 and type 2 diabetes. Neither was rs7568369 associated with type 2 diabetes; however, the minor A-allele of rs7568369 protected against obesity $(\mathrm{OR}=0.90(0.84-0.96), P=0.001)$ and in studies of quantitative traits $(n=5,535)$ the variant associated with decreased body mass index $(P=0.002)$ and waist circumference $(P=0.003)$. The $-1119 \mathrm{G}>\mathrm{A}$ and $-614 \mathrm{G}>\mathrm{A}$ variants were not associated with obesity or type 2 diabetes. Conclusion: We identified a novel association between the minor A-allele of KLF7 rs7568369 and protection against obesity in the Danish population.
\end{abstract}

European Journal of Endocrinology $160603-609$

\section{Introduction}

Obesity, type 2 diabetes and the accompanying risk of premature cardiovascular morbidity and mortality are becoming rapidly growing health burdens. Environmental and genetic factors contribute to the development of obesity and type 2 diabetes. The Krüppel-like factor (KLF) family of 15 zinc-finger-containing transcription factors has been reported to be involved in cellular growth, proliferation, and differentiation (1-3). A potential role in fat metabolism has been described for some of the KLF family members. Thus, KLF2 is a negative regulator of adipocyte differentiation via inhibition of peroxisome proliferator-activated receptor (PPAR) $\gamma$ (4), and KLF15 can induce adipocyte maturation and expression of the glucose transporter
GLUT4 (5). KLF7, ubiquitous KLF, is expressed in adipocytes and in a variety of human tissues including pancreas, skeletal muscle, and liver $(6,7)$ and overexpression of KLF7 in human preadipocytes has been shown to suppress adipogenesis (6). Particularly, KLF7 was reported to inhibit adiponectin gene expression in adipocytes (6), and the green tea polyphenol $(-)$-catechin was found to markedly enhance the expression of adiponectin and increase glucose-uptake into 3T3-L1 adipocytes, which was accompanied by the down-regulation of KLF7 (8). When it comes to the potential involvement of the KLF family in the pathogenesis of common metabolic disorders like type 2 diabetes, previous studies involving 728 type 2 diabetic cases and 1491 control individuals of French origin have examined the genes encoding KLF2, KLF3, KLF4, 
KLF5, KLF6, KLF12, KLF13, KLF15, and KLF16; however, no robust associations between variants of these KLF genes and type 2 diabetes could be demonstrated (9). Interestingly, the major A-allele of rs2302870 in KLF7 was reported to associate with type 2 diabetes in a Japanese population (10). KLF7 which is located on chromosome $2 \mathrm{q} 32$ spans $\sim 85 \mathrm{~kb}$ and consists of four exons (7). According to HapMap (www.hapmap.org, data release \#23a) KLF7 harbors numerous single nucleotide polymorphisms (SNPs), especially in introns, and linkage disequilibrium (LD) structure analysis suggests that pairwise tagging of 44 SNPs will be needed to capture the locus variation for SNPs with minor allele frequency (MAF) $>0.05$ with $r^{2}>0.8$. Instead of such an exhaustive and resource demanding tagSNP approach, we decided to identify variation in the putative promoter region, the coding regions, exon/intron boundaries, and 3'- untranslated region (UTR) of KLF7 in the present study, and these regions were re-sequenced in 48 Danish overweight or obese patients with type 2 diabetes. Hence, the aim of the present study was to investigate identified common variants of KLF7 for association with type 2 diabetes and obesity in a Danish population.

\section{Subjects and methods}

The screening for variation in KLF7 was performed in 48 unrelated overweight or obese individuals with type 2 diabetes (age $65 \pm 10$ years (mean \pm s.D.) and body mass index (BMI) $31.3 \pm 5.1 \mathrm{~kg} / \mathrm{m}^{2}$ ). All individuals were recruited from the Steno Diabetes Center (SDC), Copenhagen, Denmark.

Case-control studies of obesity were performed in $n=14818$ (rs2302870) or $n=14611$ (rs7568369) Danish individuals from three study groups: i) from the population-based Inter99 study sample $\left(n_{\text {total }}=6784\right)$ we included $n=5774(\operatorname{rs} 2302870)$ or $n=5535$ (rs7568369) treatment-naïve successfully genotyped individuals of Danish nationality recruited from Research Centre for Prevention and Health (ClinicalTrials.gov Identifier: NCT00289237, (11)); ii) the Danish subsample of ADDITION (Anglo-DanishDutch-Study of Intensive Treatment in People with Screen-Detected Diabetes in Primary Care) study sample $(n=8407$ (rs2302870) or $n=8459$ (rs7568369)) sampled by the Department of General Practice at the University of Aarhus, Denmark (ClinicalTrials.gov Identifier: NCT00237548, (12)); and iii) a populationbased group of unrelated middle-aged individuals $(n=638 \quad($ rs2302870) or $n=618 \quad($ rs7568369) $)$ examined at SDC. Individuals with a previous diagnosis of type 2 diabetes were excluded from studies of obesity as their medication might affect their body weight. Individuals were defined as lean (BMI $<25 \mathrm{~kg} / \mathrm{m}^{2}$ ), overweight/obese (BMI $\geq 25 \mathrm{~kg} / \mathrm{m}^{2}$ ) or obese (BMI $\geq 30 \mathrm{~kg} / \mathrm{m}^{2}$ ). The study participants were further stratified according to sex-specific waist circumference. In the latter context, we defined individuals with a waist circumference $<80 \mathrm{~cm}$ (women) or $<94 \mathrm{~cm}$ (men) as lean, whereas overweight/abdominally obese individuals were $\geq 80 \mathrm{~cm}$ (women) or $\geq 94 \mathrm{~cm}$ (men), and a subgroup of abdominally obese individuals were $\geq 88 \mathrm{~cm}$ (women) or $\geq 102 \mathrm{~cm}$ (men) around the waist.

Case-control studies of type 2 diabetes were performed in 4891 (rs2302870) or 4689 (rs7568369) glucose-tolerant individuals and 3886 (rs2302870) or 3848 (rs7568369) patients with type 2 diabetes from the above-mentioned study samples plus a sample of unrelated type 2 diabetes patients from the outpatient clinic at SDC $(n=1920(\mathrm{rs} 2302870)$ or $n=1870$ (rs7568369)). Diabetes was diagnosed according to the 1999 WHO criteria (13).

All participants were of Danish nationality and informed written consent was obtained before participation. Studies were approved by regional ethics committees and were in accordance with the principles of the Helsinki Declaration II.

\section{Anthropometrical and biochemical measurements}

Body weight and height were measured with individuals wearing light indoor clothing without shoes. Waist circumference was measured midway between the iliac crest and the lower costal margin. Blood samples were taken in the morning after an overnight fast of at least 8 h. Plasma glucose, serum insulin, C-peptide, and lipids were measured using SDC standard methods.

\section{Polymorphism search and genotyping}

Polymorphism search in the putative promoter region (we selected $\sim 1200 \mathrm{bp}$ upstream of the translation start site), the coding regions, exon/intron boundaries, and 3'-UTR of KLF7 (Ensembl Gene ID: ENSG000001 18263) was performed by bidirectional nucleotide sequencing (MWG, Ebersberg, Germany) on genomic DNA extracted from human leucocytes, with subsequent analysis for variants applying SeqScape Software version 2.5 (Applied Biosystems, Foster City, CA, USA). Primers and PCR conditions for the polymorphism search are available on request. Genotyping of rs2302870, rs7568369, $-1119 \mathrm{G}>\mathrm{A}$, and -614 $\mathrm{G}>\mathrm{A}$ (relative to the translation start site, forward orientation, top strand) was performed using TaqMan allelic discrimination (KBioscience, Herts, UK), the genotyping success rates were 97, 96, 97, and 99\% respectively, and among 966 replicate samples error rates of $0.0,0.3,0.1$, and $0.0 \%$ respectively, were observed. Genotype distributions for all variants obeyed Hardy-Weinberg equilibrium $(P>0.05)$. 


\section{Statistical analyses}

For case-control studies, Fisher's exact test was used to examine differences in allele frequencies, and differences in genotype distributions were calculated applying an additive logistic regression model while adjusting for sex and age. A general linear model tested variables of quantitative traits for differences between genotype groups were adjusted for sex and age (and BMI where appropriate). The Benjamini-Hochberg method (14) was used separately for each variant to correct for multiple testing. A test for homogeneity between the SDC population-based sample, Inter99, and the ADDITION study was performed by means of the Mantel-Haenszel method (fixed effects model), and showed no heterogeneity between studies $(P=0.88)$. Analyses were performed with RGui version 2.5.0 (http://www.r-project.org/). A P-value $<0.05$ was considered significant.

\section{Results}

By re-sequencing the putative promoter region, the coding regions, exon/intron boundaries, and $3^{\prime}$-UTR of the KLF7 in 48 Danish overweight or obese patients with type 2 diabetes, we identified four SNPs with a MAF $>5 \%$ : three in the putative promoter region $(-1119 \mathrm{G}>\mathrm{A}(\mathrm{MAF}=35 \%),-963 \mathrm{C}>\mathrm{A}(\mathrm{rs} 75683-$ $69, \mathrm{MAF}=33 \%)$, and $-614 \mathrm{G}>\mathrm{A}(\mathrm{MAF}=7 \%)$ relative to the translation start site, forward orientation, top strand) and IVS2 + $35092 \mathrm{~A}>\mathrm{C}$ (rs2302870, MAF $=12 \%$ ). These four variants were in low pairwise $\mathrm{LD}\left(r^{2}<0.35\right)$. No variants were identified in the coding region or $3^{\prime}$-UTR of KLF7.

In case-control studies of type 2 diabetes including 4891 glucose-tolerant individuals and 3886 patients with type 2 diabetes there was no difference in the frequency of the minor C-allele of rs2302870 and no difference in genotype distribution between the two groups (Table 1). Neither was rs7568369 associated with type 2 diabetes (Table 1), and nor were the two promoter variants $-1119 \mathrm{G}>\mathrm{A}$ and $-614 \mathrm{G}>\mathrm{A}$ (data not shown).

In case-control studies of 14611 Danes from the Inter99, ADDITION, and the SDC study samples dichotomized according to BMI or sex-specific waist circumference the major C-allele of rs7568369 variant was associated with measures of body fat accumulation (Table 2). The frequency of the minor A-allele of rs7568369 was statistically significantly lower among overweight/obese individuals (34.1\% (33.5-34.8\%)) and obese individuals $(33.5 \%(32.4-34.5 \%))$ defined by BMI compared with non-obese individuals $(35.9 \%$ $(34.9-36.9 \%))\left(\mathrm{OR}=0.93(0.88-0.98), P_{\mathrm{MAF}}=0.004\right.$; and $\mathrm{OR}=0.90(0.84-0.96), P_{\mathrm{MAF}}=0.001$ respectively $)$. Differences in genotype distributions were also shown between non-obese and overweight/obese or obese individuals $\left(\mathrm{OR}=0.93(0.88-0.98), P_{\mathrm{GD}}=0.007\right.$; and $\mathrm{OR}=0.90(0.84-0.96), P_{\mathrm{GD}}=0.001$ respectively $)$. Stratifying individuals into four BMI subgroups (BMI $<25$, $25 \leq \mathrm{BMI}<30, \quad 30 \leq \mathrm{BMI}<35$, and $\mathrm{BMI} \geq 35 \mathrm{~kg} / \mathrm{m}^{2}$ ) showed a decrease in MAF with increasing BMI $(\mathrm{BMI}<25: \quad \mathrm{MAF}=35.9 \% \quad(34.9-36.9 \%) ; 25 \leq \mathrm{BMI}<$ 30: $\mathrm{MAF}=34.5 \% \quad(33.7-35.4 \%), \quad 30 \leq \mathrm{BMI}<35$ : $\mathrm{MAF}=33.9 \% \quad(32.7-35.2 \%)$ and $\mathrm{BMI} \geq 35 \mathrm{~kg} / \mathrm{m}^{2}$ : $\mathrm{MAF}=32.3 \%$ (30.3-34.3\%), Fig. 1).

Similarly, the frequency of the minor A-allele of rs7568369 was statistically significantly lower among overweight/abdominally obese and abdominally obese individuals defined by sex-specific waist circumference compared with lean individuals (Table 2).

For rs2302870 $(n=14818)$ no statistical significant difference in MAF was found among overweight/obese individuals and obese individuals defined by BMI compared with non-obese individuals, and no differences in genotype distributions were shown (Table 2). However, the frequency of the minor C-allele of rs2302870 was significantly higher in overweight/ abdominally obese individuals (10.9\% (10.5-11.4\%))

Table 1 Genotype distribution, minor allele frequencies, and odds ratios for rs2302870 $(n=8777)$ and rs7568369 ( $n=8537)$ in $K L F 7$ among individuals with normal glucose tolerance and patients with type 2 diabetes.

\begin{tabular}{|c|c|c|c|c|c|c|c|}
\hline & $n(\mathrm{~m} / \mathrm{w})$ & & Genotype & & MAF $(95 \% \mathrm{Cl})$ & $\begin{array}{l}\text { Unadjusted }^{*} \\
\text { Allele frequency } \\
\text { model OR } \\
(95 \% \mathrm{Cl})\end{array}$ & $\begin{array}{c}\text { Adjusted } \dagger \\
\text { Additive model } \\
\text { OR }(95 \% \mathrm{Cl})\end{array}$ \\
\hline $\begin{array}{l}\text { rs2302870 } \\
\text { NGT }\end{array}$ & $4891(2272 / 2619)$ & $\begin{array}{l}\text { A/A } \\
3938(81)\end{array}$ & $\begin{array}{l}\text { A/C } \\
899(18)\end{array}$ & $\begin{array}{l}\mathbf{C} / \mathbf{C} \\
54(1)\end{array}$ & $10.3(9.7-10.9)$ & & \\
\hline Type 2 diabetes & $3886(2304 / 1582)$ & $3119(80)$ & $728(19)$ & $39(1)$ & $10.4(9.7-11.1)$ & $\begin{array}{c}1.01(0.91-1.11) \\
P_{\mathrm{MAF}}=0.88\end{array}$ & $\begin{array}{c}1.00(0.87-1.12) \\
P_{\mathrm{GD}}=0.74\end{array}$ \\
\hline $\begin{array}{l}\text { rs7568369 } \\
\text { NGT }\end{array}$ & $4689(2193 / 2496)$ & $\begin{array}{l}\text { C/C } \\
1937(41)\end{array}$ & $\begin{array}{l}\text { C/A } \\
2176(47)\end{array}$ & $\begin{array}{l}\text { A/A } \\
576(12)\end{array}$ & $35.5(34.5-36.5)$ & & \\
\hline Type 2 diabetes & $3848(2275 / 1573)$ & $1645(42)$ & $1720(45)$ & $483(13)$ & $34.9(33.8-36.0)$ & $\begin{array}{c}0.98(0.92-1.05) \\
P_{\mathrm{MAF}}=0.43\end{array}$ & $\begin{array}{c}0.98(0.91-1.04) \\
P_{\mathrm{GD}}=0.66\end{array}$ \\
\hline
\end{tabular}

Data are number of individuals with each genotype (\% of each group), percentage frequencies of the minor allele (MAF) (95\% $\mathrm{Cl})$, and odds ratio (OR) (95\% $\mathrm{Cl})$. ${ }^{*} P$-values (unadjusted) compare differences in allele frequencies ( $P_{\mathrm{MAF}}$ ) between normal glucose-tolerant individuals (NGT) and patients with type 2 diabetes, using Fisher's exact test.

†Differences in genotype distribution $\left(P_{\mathrm{GD}}\right)$ were calculated applying an additive logistic regression model, while adjusting for sex and age. 
Table 2 Genotype distribution, minor allele frequencies, and odds ratios for rs2302870 ( $n=14$ 818) and rs7568369 ( $n=14611)$ among individuals stratified according to genotype and body mass index subgroup or sex-specific waist circumference subgroup.

\begin{tabular}{|c|c|c|c|c|c|c|c|}
\hline & $n(\mathrm{~m} / \mathrm{w})$ & & Genotype & & MAF $(95 \% \mathrm{Cl})$ & $\begin{array}{c}\text { Unadjusted* } \\
\text { Allele frequency } \\
\text { model OR }(95 \% \mathrm{Cl})\end{array}$ & $\begin{array}{c}\text { Adjusted } \dagger \\
\text { Additive model OR } \\
(95 \% \mathrm{Cl})\end{array}$ \\
\hline \multicolumn{2}{|l|}{$\begin{array}{l}\text { rs2302870 } \\
\text { BMl }\end{array}$} & A/A & $A / C$ & $\mathrm{C} / \mathrm{C}$ & & & \\
\hline$<25 \mathrm{~kg} / \mathrm{m}^{2}$ & $4683(1928 / 2755)$ & $3780(81)$ & $856(18)$ & $47(1)$ & $10.1(9.5-10.8)$ & & \\
\hline$\geq 25 \mathrm{~kg} / \mathrm{m}^{2}$ & $10135(5837 / 4298)$ & $8086(80)$ & 1913 (19) & $136(1)$ & $10.8(10.4-11.2)$ & $\begin{array}{c}1.07(0.99-1.16) \\
P_{\mathrm{MAF}}=0.10\end{array}$ & $\begin{array}{c}1.06(0.97-1.15) \\
P_{\mathrm{GD}}=0.18\end{array}$ \\
\hline$\geq 30 \mathrm{~kg} / \mathrm{m}^{2}$ & $3871(1964 / 1907)$ & $3104(80)$ & 714 (19) & $53(1)$ & $10.6(9.9-11.3)$ & $\begin{array}{c}1.05(0.95-1.16) \\
P_{\mathrm{MAF}}=0.34\end{array}$ & $\begin{array}{c}1.05(0.95-1.16) \\
P_{\mathrm{GD}}=0.34\end{array}$ \\
\hline \multicolumn{8}{|r|}{$T_{G D}-0.04$} \\
\hline $\begin{array}{l}<80 \mathrm{~cm}(\mathrm{w}) \text { or } \\
<94 \mathrm{~cm}(\mathrm{~m})\end{array}$ & $5326(2818 / 2508)$ & $4314(81)$ & 959 (18) & $53(1)$ & $10.0(9.4-10.6)$ & & \\
\hline $\begin{array}{l}\geq 80 \mathrm{~cm}(\mathrm{w}) \text { or } \\
\geq 94 \mathrm{~cm}(\mathrm{~m})\end{array}$ & $9474(4935 / 4539)$ & $7533(80)$ & $1811(19)$ & $130(1)$ & $10.9(10.5-11.4)$ & $\begin{array}{c}1.10(1.02-1.20) \\
P_{\mathrm{MAF}}=0.01\end{array}$ & $\begin{array}{c}1.09(1.01-1.18) \\
P_{\mathrm{GD}}=0.03\end{array}$ \\
\hline $\begin{array}{l}\geq 88 \mathrm{~cm}(\mathrm{w}) \text { or } \\
\geq 102 \mathrm{~cm}(\mathrm{~m})\end{array}$ & $5700(2701 / 2999)$ & $4517(79)$ & 1104 (19) & $79(1)$ & $11.1(10.5-11.7)$ & $\begin{array}{c}1.12(1.03-1.22) \\
P_{\mathrm{MAF}}=0.001^{*}\end{array}$ & $\begin{array}{c}1.10(1.01-1.21) \\
P_{\mathrm{GD}}=0.04\end{array}$ \\
\hline $\begin{array}{l}\text { rs7568369 } \\
\text { BMI }\end{array}$ & & $\mathrm{C} / \mathrm{C}$ & C/A & A/A & & & \\
\hline$<25 \mathrm{~kg} / \mathrm{m}^{2}$ & $4579(1903 / 2676)$ & $1883(41)$ & $2108(46)$ & $588(13)$ & $35.9(34.9-36.9)$ & & \\
\hline$\geq 25 \mathrm{~kg} / \mathrm{m}^{2}$ & $10032(5790 / 4242)$ & $4373(43)$ & $4473(45)$ & $1186(12)$ & $34.1(33.5-34.8)$ & $\begin{array}{c}0.93(0.88-0.98) \\
P_{\mathrm{MAF}}=0.004^{*}\end{array}$ & $\begin{array}{c}0.93(0.88-0.98) \\
P_{\mathrm{GD}}=0.007^{*}\end{array}$ \\
\hline$\geq 30 \mathrm{~kg} / \mathrm{m}^{2}$ & $3852(1960 / 1892)$ & $1718(44)$ & $1691(44)$ & $443(12)$ & $33.5(32.4-34.5)$ & $\begin{array}{c}0.90(0.84-0.96) \\
P_{\mathrm{MAF}}=0.001^{*}\end{array}$ & $\begin{array}{c}0.90(0.84-0.96) \\
P_{\mathrm{GD}}=0.001^{*}\end{array}$ \\
\hline \multicolumn{8}{|l|}{ Waist } \\
\hline $\begin{array}{l}<80 \mathrm{~cm}(\mathrm{w}) \text { or } \\
<94 \mathrm{~cm}(\mathrm{~m})\end{array}$ & $5201(2765 / 2436)$ & $2141(41)$ & 2409 (46) & $651(13)$ & $35.7(34.8-36.6)$ & & \\
\hline $\begin{array}{l}\geq 80 \mathrm{~cm}(\mathrm{w}) \text { or } \\
\geq 94 \mathrm{~cm}(\mathrm{~m})\end{array}$ & $9390(4915 / 4475)$ & $4108(44)$ & $3161(44)$ & $1121(12)$ & $34.1(33.4-34.8)$ & $\begin{array}{c}0.93(0.89-0.98) \\
P_{\mathrm{MAF}}=0.007^{\star}\end{array}$ & $\begin{array}{c}0.94(0.89-0.98) \\
P_{\mathrm{GD}}=0.01^{*}\end{array}$ \\
\hline $\begin{array}{l}\geq 88 \mathrm{~cm}(\mathrm{w}) \text { or } \\
\geq 102 \mathrm{~cm}(\mathrm{~m})\end{array}$ & $5663(2689 / 2974)$ & $2523(45)$ & $2495(44)$ & $645(11)$ & $33.4(32.5-34.3)$ & $\begin{array}{l}0.90(0.86-0.96) \\
\quad P_{\mathrm{MAF}}=5 \times 10^{-4 \star}\end{array}$ & $\begin{array}{l}0.91(0.85-0.95) \\
\quad P_{\mathrm{GD}}=3 \times 10^{-4 *}\end{array}$ \\
\hline
\end{tabular}

Data are number of individuals with each genotype (\% of each group), percentage frequencies of the minor allele (MAF) $(95 \% \mathrm{Cl})$, and odds ratio $(\mathrm{OR})(95 \% \mathrm{Cl})$. ${ }^{*} P$-values (unadjusted) compare differences in allele frequencies $\left(P_{\text {MAF }}\right)$ between individuals with a BMl below $25 \mathrm{~kg} / \mathrm{m}^{2}$, and above 25 or $30 \mathrm{~kg} / \mathrm{m}^{2}$ respectively; or individuals with a waist circumference below $80 \mathrm{~cm}$ (women) or $94 \mathrm{~cm}$ (men), and above $80 \mathrm{~cm}$ (women) or $94 \mathrm{~cm}$ (men), or $88 \mathrm{~cm}$ (women) or $102 \mathrm{~cm}$ (men) respectively, using Fisher's exact test.

†Differences in genotype distribution $\left(P_{\mathrm{GD}}\right.$ ) between individuals with a BMI below $25 \mathrm{~kg} / \mathrm{m}^{2}$, and above 25 or $30 \mathrm{~kg} / \mathrm{m}^{2}$ respectively; or individuals with a waist circumference below $80 \mathrm{~cm}$ (women) or $94 \mathrm{~cm}$ (men), and above $80 \mathrm{~cm}$ (women) or $94 \mathrm{~cm}$ (men), or $88 \mathrm{~cm}$ (women) or $102 \mathrm{~cm}$ (men) respectively, were calculated applying an additive logistic regression model, while adjusting for sex and age. * $P$-values remained significant after Benjamini-Hochberg correction.

and abdominally obese individuals (11.1\% (10.5$11.7 \%)$ ) compared with lean individuals $(10.0 \%(9.4-$ $10.6 \%)$ ) defined by sex-specific waist circumference $\left(\mathrm{OR}=1.10(1.02-1.20), P_{\mathrm{MAF}}=0.01 ;\right.$ and $\mathrm{OR}=1.12$ (1.03-1.22), $\quad P_{\mathrm{MAF}}=0.001$ respectively), and differences in genotype distributions were found between lean and overweight/abdominally obese individuals $\left(\mathrm{OR}=1.09 \quad(1.01-1.18), P_{\mathrm{GD}}=0.03\right)$ and between lean and abdominally obese individuals $\left(\mathrm{OR}=1.10\right.$ (1.01-1.21), $\left.P_{\mathrm{GD}}=0.04\right)$.

The two promoter variants $-1119 \mathrm{G}>\mathrm{A}$ and -614 $\mathrm{G}>\mathrm{A}$ were not associated with obesity defined by BMI or sex-specific waist circumference (data not shown).

In the population-based Inter99 sample involving 5774 treatment-naïve, unrelated individuals the minor C-allele of rs2302870 was nominally associated with obesity-related quantitative traits of higher BMI, waist circumference, waist-to-hip ratio, and body weight ( $P=0.02,0.03,0.03$, and 0.04 respectively), while there was no association with fasting plasma glucose, serum insulin, and C-peptide (Table 3). Furthermore, no association of rs2302870 with homeostasis model assessment of insulin resistance index (HOMA-IR) was found (Table 3).

The rs7568369 minor A-allele was associated with obesity-related quantitative traits of lower BMI, waist circumference, and body weight (effect per minor A-allele: -0.27 (95\% CI: $-0.44--0.10) \mathrm{kg} / \mathrm{m}^{2}$, $-0.67(-1.12--0.23) \mathrm{cm}$, and $-0.61(-1.16-$ $-0.06) \mathrm{kg}$ respectively; $P=0.002,0.003$, and 0.03 respectively, (effect size estimates and $P$-values were adjusted for age and sex)), while there was no association with waist-to-hip ratio, HOMA-IR, fasting plasma glucose, serum insulin, and C-peptide (Table 3). The two promoter variants $-1119 \mathrm{G}>\mathrm{A}$ and -614 $\mathrm{G}>\mathrm{A}$ were not associated with any of the measured quantitative traits (data not shown).

\section{Discussion}

In a screening for variation in the KLF7 four variants with a MAF $>5 \%$ were identified. Of these variants the major A-allele of rs2302870 had previously been 


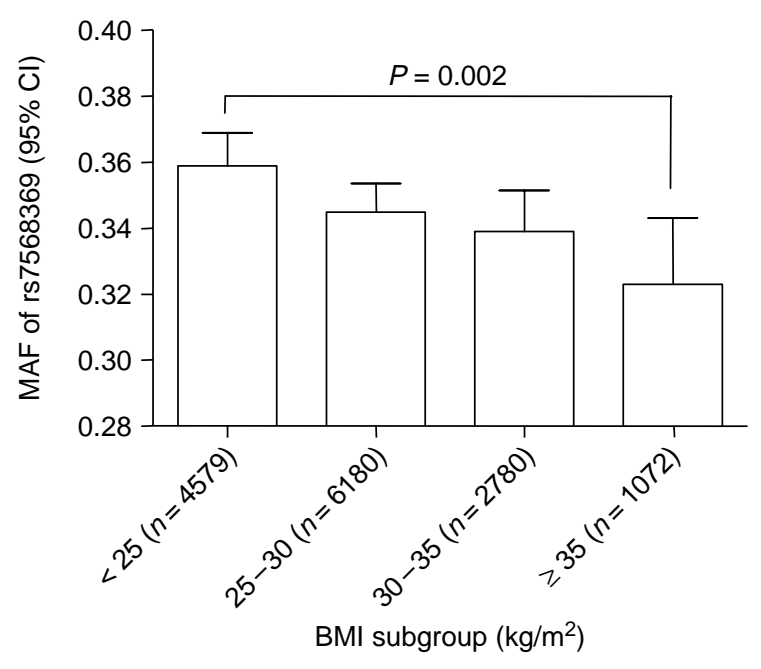

Figure 1 Stratification of individuals from the population-based Inter99 and Steno Diabetes Center study samples and the ADDITION study into four $\mathrm{BMI}$ subgroups $(\mathrm{BMI}<25,25 \leq \mathrm{BMI}<30$, $30 \leq \mathrm{BMI}<35$, and $\mathrm{BMI} \geq 35 \mathrm{~kg} / \mathrm{m}^{2}$ ) showed a decrease in frequency of the minor A-allele (MAF) of rs7568369 with increasing BMI. A statistically significant difference in MAF was observed for individuals with a BMl $<25$ and $\geq 35 \mathrm{~kg} / \mathrm{m}^{2}(\mathrm{OR}=0.85(95 \% \mathrm{Cl}$ : 0.77-0.94), $P=0.002$ ).

associated with type 2 diabetes (10); however, we failed to replicate this finding. Contrary, in the populationbased study of quantitative traits, we identified an association between the minor C-allele of rs2302870 and a higher BMI, waist circumference, waist-to-hip ratio and body weight, although these nominal associations were abolished after Benjamini-Hochberg correction for multiple testing. Furthermore, in casecontrol studies of abdominal obesity defined by sexspecific waist-circumference (Table 2), we found an association with the minor C-allele of rs2302870, although only the difference in MAF between lean and abdominally obese individuals remained significant after Benjamini-Hochberg correction. Additionally, case-control studies of obesity defined by BMI did not confirm these findings, indicating that rs2302870 does not have a major impact on the risk of obesity or type 2 diabetes in the Danish population. The discrepancy between the results of the case-control studies of type 2 diabetes in the Japanese (10) and in the Danish study samples might be due to the differences in the number of individuals included. The Japanese study involved 1130 patients with type 2 diabetes and 564 control individuals, and was repeated in 560 patients with type 2 diabetes and 359 control individuals, whereas the present study included 3886 patients with type 2 diabetes and 4891 glucose-tolerant individuals. There is barely no difference in the frequency of the variant in the two populations $(\mathrm{MAF}=12 \%$ and $13 \%$ in CEU and JPT HapMap respectively). Yet, a difference in ethnicity is a possibility to explain the divergent results, since rs2302870 is likely to be in strong LD with a causative variant that may be different in the two populations due to difference in LD structure within or near the KLF7 locus.

Case-control studies of obesity defined by BMI and sex-specific waist circumference demonstrated a novel association between the major C-allele of rs7568369 in the putative promoter region of KLF7 and obesity. This finding may be robust, since the same variant associated with obesity-related quantitative measures of BMI and waist circumference in the population-based Inter99 study sample, and the findings remained significant after Benjamini-Hochberg correction for multiple testing, indicating a protective effect of the minor A-allele of rs7568369 against obesity. If replicated, our findings suggest that variation in KLF7 may influence body fat among Europeans.

According to HapMap (data release \#23a) rs7568369 is monomorphic (the major allele is found with a frequency of $100 \%$ in all HapMap populations) which is in conflict with our findings of a common variant (MAF 35\%) at this particular position in the sequence. To ensure that it is in fact rs7568369 we have examined, we randomly picked three individuals homozygous for the major rs7568369 allele, two heterozygous carriers, and one individual homozygous for the minor rs7568369 allele identified by the initial sequencing. Re-sequencing and genotyping revealed $100 \%$ concordance, confirming that rs7568369 has a MAF of approximately $35 \%$ in the Danish population.

In the present study, we identified variation in the putative promoter region, the coding regions, exon/intron boundaries, and 3'- UTR of KLF7. We can not exclude the possibility that other variants within this locus have influence on the risk of common metabolic disorders like type 2 diabetes and obesity, and future studies applying a tagging approach of the entire KLF7 locus would be relevant.

In a search of available web-based results of genomewide association studies for KLF7 SNPs and their potential association with type 2 diabetes or BMI in the diabetes genetics initiative (DGI) database (www.broad.mit.edu/diabetes/) (15) only one out of 13 KLF7 SNP (rs1263625) was associated with type 2 diabetes $(P=0.03)$, and none of the investigated DGI SNPs were associated with BMI. This variant has previously been studied in relationship with type 2 diabetes in the Japanese population; however, no association has been found (10). The rs2302870 was not in LD with any of the SNPs in the DGI database, whereas LD structure for rs7568369 was unavailable.

As it has previously been shown that KLF7 expression has an inhibitory effect on adipogenesis $(6,10)$, it is hypothesized that variation in KLF7 may confer susceptibility to obesity in part by affecting adipocyte function. The potential mechanism is as yet unknown; however, it could be speculated that KLF7 might be an important regulator of the expression of 
Table 3 Anthropometric and metabolic characteristics of treatment-naive unrelated individuals from the population-based Inter99 sample stratified according to genotype of rs2302870 $(n=5774)$ or rs7568369 $(n=5535)$.

\begin{tabular}{|c|c|c|c|c|}
\hline & & Genotype & & $P_{\text {add }}$ \\
\hline rs2302870 & A/A & $\mathrm{A} / \mathrm{C}$ & $\mathrm{C} / \mathrm{C}$ & \\
\hline$n(\mathrm{~m} / \mathrm{w})$ & $4652(2298 / 2354)$ & $1060(534 / 526)$ & $62(34 / 28)$ & \\
\hline Age (years) & $46 \pm 8$ & $46 \pm 8$ & $46 \pm 8$ & \\
\hline BMI $\left(\mathrm{kg} / \mathrm{m}^{2}\right)$ & $26.1 \pm 4.5$ & $26.5 \pm 4.9$ & $26.5 \pm 4.3$ & 0.02 \\
\hline Waist $(\mathrm{cm})$ & $86 \pm 13$ & $87 \pm 14$ & $87 \pm 12$ & 0.03 \\
\hline Waist-to-hip ratio & $0.8 \overline{5} \pm 0.09$ & $0.86 \pm 0.09$ & $0.86 \pm 0.09$ & 0.03 \\
\hline Weight $(\mathrm{kg})$ & $77.8 \pm 15.8$ & $79.0 \pm 17.0$ & $79.0 \pm 14.0$ & 0.04 \\
\hline Fasting plasma glucose $(\mathrm{mmol} / \mathrm{l})$ & $5.5 \pm 0.8$ & $5.6 \pm 1.0$ & $5.6 \pm 1.0$ & 0.81 \\
\hline Fasting serum insulin $(\mathrm{pmol} / \mathrm{l})$ & $42 \pm 28$ & $43 \pm 29$ & $47 \pm 30$ & 0.82 \\
\hline Fasting serum C-peptide (pmol/l) & $591 \pm 267$ & $615 \pm 299$ & $607 \pm 239$ & 0.27 \\
\hline HOMA-IR $(\mathrm{pmol} / \mathrm{I} \times \mathrm{mmol} / \mathrm{l})$ & $10.5 \pm 8.0$ & $10.9 \pm 8.5$ & $11.9 \pm 8.0$ & 0.87 \\
\hline Fasting s-triglycerides $(\mathrm{mmol} / \mathrm{l})$ & $1.3 \pm 1.3$ & $1.4 \pm 1.6$ & $1.2 \pm 0.9$ & 0.59 \\
\hline Fasting $s$-total cholesterol $(\mathrm{mmol} / \mathrm{l})$ & $5.5 \pm 1.1$ & $5.5 \pm 1.1$ & $5.6 \pm 1.2$ & 0.63 \\
\hline Fasting $s$-HDL cholesterol ( $\mathrm{mmol} / \mathrm{l})$ & $1.4 \pm 0.4$ & $1.4 \pm 0.4$ & $1.4 \pm 0.3$ & 0.91 \\
\hline rs7568369 & $\mathrm{C} / \mathrm{C}$ & C/A & A/A & \\
\hline$n(\mathrm{~m} / \mathrm{w})$ & $2314(1164 / 1150)$ & $2541(1262 / 1279)$ & $680(334 / 335)$ & \\
\hline Age (years) & $46 \pm 8$ & $46 \pm 8$ & $46 \pm 8$ & \\
\hline BMI $\left(\mathrm{kg} / \mathrm{m}^{2}\right)$ & $26.4 \pm 4.7$ & $26.1 \pm 4.3$ & $25 . \overline{9} \pm 4.5$ & $0.002^{*}$ \\
\hline Waist (cm) & $87 \pm \overline{13}$ & $86 \pm \overline{13}$ & $86 \pm \overline{13}$ & $0.003^{*}$ \\
\hline Waist-to-hip ratio & $0.86 \pm 0.09$ & $0.85 \pm 0.09$ & $0.8 \overline{6} \pm 0.09$ & 0.10 \\
\hline Weight $(\mathrm{kg})$ & $78.7 \pm 16.7$ & $77.7 \pm 15.3$ & $77.7 \pm 16.0$ & 0.03 \\
\hline Fasting plasma glucoses $(\mathrm{mmol} / \mathrm{l})$ & $5.6 \pm 0.9$ & $5.5 \pm 0.8$ & $5.5 \pm 0.6$ & 0.12 \\
\hline Fasting serum insulin $(\mathrm{pmol} / \mathrm{l})$ & $43 \pm 28$ & $42 \pm 28$ & $40 \pm 28$ & 0.34 \\
\hline Fasting serum C-peptide (pmol/l) & $603 \pm 289$ & $593 \pm 261$ & $579 \pm 270$ & 0.96 \\
\hline HOMA-IR (pmol/l× $\times$ mol/li) & $10.9 \pm 8.4$ & $10.5 \pm 7.9$ & $10.0 \pm 7.9$ & 0.23 \\
\hline Fasting $s$-triglycerides $(\mathrm{mmol} / \mathrm{l})$ & $1.3 \pm 1.0$ & $1.3 \pm 1.7$ & $1.3 \pm 1.1$ & 0.52 \\
\hline Fasting s-total cholesterol $(\mathrm{mmol} / \mathrm{l})$ & $5.6 \pm 1.1$ & $5.5 \pm 1.1$ & $5.5 \pm 1.1$ & 0.66 \\
\hline Fasting $s-H D L$ cholesterol $(\mathrm{mmol} / \mathrm{l})$ & $1.4 \pm 0.4$ & $1.4 \pm 0.4$ & $1.4 \pm 0.4$ & 0.96 \\
\hline
\end{tabular}

Data are means \pm s.D. Calculated $P$-values were adjusted for age and sex for obesity-related quantitative traits; and for age, sex, and BMI for plasma glucose, serum insulin, serum lipids, and HOMA-IR. Values of plasma glucose, serum insulin, serum C-peptide, serum triglycerides, and HOMA-IR were logarithmically transformed before statistical analysis. HOMA-IR was calculated as fasting plasma glucose (mmol/l) multiplied by fasting serum insulin (pmol/I) divided by 22.5 . $P$-values were calculated assuming an additive model.

${ }^{*} P$-values remained significant after Benjamini-Hochberg correction. s, serum; HOMA-IR: homeostasis model assessment of insulin resistance index.

other genes functioning in the adipocytes, as KLF7 has been shown to inhibit the expression of several genes expressed in adipocytes that are crucial for adipogenesis such as adiponectin, leptin, PPAR $\gamma$, and CCAAT enhancer binding protein $\alpha(\operatorname{CEBP} \alpha)(8)$.

The obesity-associated rs7568369 might only be a marker in $\mathrm{LD}$ with a causative variant, and re-sequencing and association testing of the entire KLF7 locus and eventually functional studies are needed to clarify the role of rs7568369 and other polymorphisms in KLF7 in relation to obesity and type 2 diabetes.

\section{Declaration of interest}

K Borch-Johnsen and O Pedersen hold stock in Novo Nordisk and have received lecture fees from pharmaceutical companies. All other authors declare that there is no conflict of interest associated with this manuscript.

\section{Funding}

The study was supported by grants from the Danish Diabetes Association, the Lundbeck Foundation Centre of Applied Medical Genomics for Personalized Disease Prediction, Prevention, and Care (LUCAMP), the Danish Medical Research Council, the Danish Diabetes Association, the Velux Foundation, and the FOOD Study Group/the
Danish Ministry of Food, Agriculture and Fisheries and Ministry of Family and Consumer Affairs, grant no. 2101-05-0044. The ADDITION Denmark trial was supported by the National Health Services in the counties of Copenhagen, Aarhus, Ringkøbing, Ribe, and South Jutland in Denmark, Danish Research Foundation for General Practice, Danish Centre for Evaluation and Health Technology Assessment, The Diabetes Fund of the National Board of Health. The Danish Medical Research Council, The Aarhus University Research Foundation and Novo Nordisk Foundation. Furthermore, the trial has been given unrestricted grants from Novo Nordisk A/S, Novo Nordisk Scandinavia AB, ASTRA Denmark, Pfizer Denmark, GlaxoSmithKline Pharma Denmark, SERVIER Denmark A/S and HemoCue Denmark A/S.

\section{Acknowledgements}

The authors thank A Forman, L Wantzin, and M Stendal for technical assistance, G Lademann for secretarial support, and A L Nielsen for expertise and contributions to data and sample management.

\section{References}

1 Dang DT, Pevsner J \& Yang VW. The biology of the mammalian Krüppel-like family of transcription factors. International Journal of Biochemistry and Cell Biology 200032 1103-1121.

2 Bieker JJ. Krüppel-like factors: three fingers in many pies. Journal of Biological Chemistry 2001276 34355-34358. 
3 Black AR, Black JD \& Azizkhan-Clifford J. Sp1 and Krüppel-like factor family of transcription factors in cell growth regulation and cancer. Journal of Cellular Physiology 2001 188 143-160.

4 Banerjee SS, Feinberg MW, Watanabe M, Gray S, Haspel RL, Denkinger DJ, Kawahara R, Hauner H \& Jain MK. The Krüppel-like factor KLF2 inhibits peroxisome proliferator-activated receptorgamma expression and adipogenesis. Journal of Biological Chemistry $20032782581-2584$.

5 Gray S, Feinberg MW, Hull S, Kuo CT, Watanabe M, SenBanerjee S, DePina A, Haspel R \& Jain MK. The Krüppel-like factor KLF1 5 regulates the insulin-sensitive glucose transporter GLUT4. Journal of Biological Chemistry $200227734322-34328$.

6 Kawamura Y, Tanaka Y, Kawamori R \& Maeda S. Overexpression of Krüppel-like factor 7 regulates adipocytokine gene expressions in human adipocytes and inhibits glucose-induced insulin secretion in pancreatic beta-cell line. Molecular Endocrinology 200620 844-856.

7 Matsumoto N, Laub F, Aldabe R, Zhang W, Ramirez F, Yoshida T \& Terada M. Cloning the cDNA for a new human zinc finger protein defines a group of closely related Krüppel-like transcription factors. Journal of Biological Chemistry 1998273 28229-28237.

8 Cho SY, Park PJ, Shin HJ, Kim YK, Shin DW, Shin ES, Lee HH, Lee BG, Baik JH \& Lee TR. Catechin suppresses expression of Krüppel-like factor 7 and increases expression and secretion of adiponectin protein in 3T3-L1 cells. American Journal of PhysiologyEndocrinology and Metabolism 2007292 E1166-E1172.

9 Gutiérrez-Aguilar R, Benmezroua Y, Vaillant E, Balkau B, Marre M, Charpentier G, Sladek R, Froguel P \& Neve B. Analysis of $K L F$ transcription factor family gene variants in type 2 diabetes. BMC Medical Genetics 2007853.

10 Kanazawa A, Kawamura Y, Sekine A, Iida A, Tsunoda T, Kashiwagi A, Tanaka Y, Babazono T, Matsuda M, Kawai K,
Iiizumi T, Fujioka T, Imanishi M, Kaku K, Iwamoto Y, Kawamori R, Kikkawa R, Nakamura $\mathrm{Y} \&$ Maeda S. Single nucleotide polymorphisms in the gene encoding Krüppel-like factor 7 are associated with type 2 diabetes. Diabetologia 200548 1315-1322.

11 Jørgensen T, Borch-Johnsen K, Thomsen TF, Ibsen H, Glümer C \& Pisinger C. A randomized non-pharmacological intervention study for prevention of ischaemic heart disease: baseline results Inter99. European Journal of Cardiovascular Prevention and Rehabilitation $200310377-386$.

12 Lauritzen T, Griffin S, Borch-Johnsen K, Wareham NJ, Wolffenbuttel BH \& Rutten G. Anglo-Danish-Dutch Study of Intensive Treatment in People with Screen Detected Diabetes in Primary Care. The ADDITION study: proposed trial of the costeffectiveness of an intensive multifactorial intervention on morbidity and mortality among people with type 2 diabetes detected by screening. International Journal of Obesity and Related Metabolic Disorders 200024 (suppl 3) S6-11.

13 World Health Organization. Definition, diagnosis and classification of diabetes mellitus and its complications. Part 1: diagnosis and classification of diabetes mellitus. Geneva, 1999 WHO/ NCD/NCS/99.2.

14 Hochberg Y \& Benjamini Y. More powerful procedures for multiple significance testing. Statistics in Medicine 19909 811-818.

15 Diabetes Genetics Initiative of Broad Institute of Harvard and MIT, Lund University, Novartis Institutes of BioMedical Research. Genome-wide association analysis identifies loci for type 2 diabetes and triglyceride levels. Science 2007316 1331-1336.

Received 31 October 2008

Accepted 13 January 2009 